$$
\text { DOE/ER/45270--T/ }
$$

\title{
Ordering Phenomena in Undercooled Alloys
}

\author{
DE-FG03-86ER45270
}

\author{
Final Report (1992-6) \\ (covering work through July, 1996)
}

for the

U. S. Department of Energy

Office of Basic Energy Science

Division of Materials Science

Metallurgy and Ceramics Branch

\author{
from \\ Brent Fultz \\ Keck Laboratory of Engineering Materials 138-78 \\ California Institute of Technology \\ Pasadena, California 91125 \\ fax: 818 795-6132
}

DISTRIBUTION OF THIS DOCUMENT Is UNLIMITED NASTER 


\section{DISCLAIMER}

This report was prepared as an account of work sponsored by an agency of the United States Government. Neither the United States Government nor any agency thereof, nor any of their employees, makes any warranty, express or implied, or assumes any legal liability or responsibility for the accuracy, completeness, or usefulness of any information, apparatus, product, or process disclosed, or represents that its use would not infringe privately owned rights. Reference herein to any specific commercial product, process, or service by trade name, trademark, manufacturer, or otherwise does not necessarily constitute or imply its endorsement, recommendation, or favoring by the United States Government or any agency thereof. The views and opinions of authors expressed herein do not necessarily state or reflect those of the United States Government or any agency thereof. 


\section{DISCLAIMER}

Portions of this document may be illegible electronic image products. Images are produced from the best available original document. 


\section{Overview}

Most of the work performed under this grant was on the topic of kinetics of ordering in undercooled alloys. Especially in the last year, however, the direction changed to a study of vibrational entropy of alloy phases.

\section{Kinetics of Ordering \\ 2.A. Theory and Monte Carlo Simulations}

Much of the work performed under this grant was devoted to using modern ideas in kinetics to understand atom movements in metallic alloys far from thermodynamic equilibrium. Kinetics arguments were based explicitly on the vacancy mechanism for atom movements. The emphasis was on how individual atom movements are influenced by the local chemical environment of the moving atom, and how atom movements cause changes in the local chemical environments. I formulated a kinetic master equation method to treat atom movements on a crystal lattice with a vacancy mechanism. Some of these analyses $[3,10,16]$ are as detailed as any treatment of the statistical kinetics of atom movements in crystalline alloys. Three results came from this work. Chronologically they were:

1) A recognition that tracking time dependencies is not necessarily the best way to study kinetic phenomena. If multiple order parameters can be measured in a material, the "kinetic path" through the space spanned by these order parameters may be just as informative about the chemical factors that affect atom movements $[2,3,5-7,9-11,14-$ $16,18,19,21,23,24,26,36,37]$.

2) Kinetic paths need not follow the steepest gradient of the free energy function (this should be well-known), and for alloys far from equilibrium the free energy function can be almost useless in describing kinetic behavior. This is why the third result surprised me.

3) In cluster approximations with multiple order parameters, saddle points are common features of free energy functions. Interestingly, kinetic processes stall or change time scale when the kinetic path approaches a state at a saddle point in the free energy function, even though these states exist far from thermodynamic equilibrium. I term such a state a "pseudostable" (falsely stable) state $[6,21,26]$. I have also studied these phenomena by. more "exact" Monte Carlo simulations. The kinetic paths showed features similar to those found in analytical theories. I found that a microstructure with interfaces arranged in space as a periodic minimal surface is a probably an alloy at a saddle point in its free energy function $[21,26,37]$. 


\section{B. Experiments}

It is optimistic to expect direct connections between theoretical work in statistical kinetics and experimental measurements with real alloys. Nevertheless, our experimental studies of kinetic paths of ordering in $\mathrm{Fe}_{3} \mathrm{Al}$ and other alloys identified phenomena that are purely kinetic, and contrary to expectations from thermodynamics. This work used primarily Mössbauer spectrometry $[2,7,8,11,14,17,20,22,23,24,26]$, to provide a detailed counting of ${ }^{57} \mathrm{Fe}$ atoms having different numbers of first neighbor Al atoms. Some work was also performed with EXELFS spectrometry [1,29]. We have measured a wide variety of kinetic paths $[5,7,11,14,17,23,24,26]$, but my favorite is our observation of $B 32$ ordering in $\mathrm{Fe}_{3} \mathrm{Al}$, which seems thermodynamically impossible $[7,11,26]$. We can explain well the transient appearance of the B32 state by the kinetic master equation method or by Monte Carlo simulations, and we can show that these states of B32 order are at saddle points of a free energy in the point approximation.

In other work performed under this grant, we measured the critical temperatures for the $\mathrm{DO}_{3}-\mathrm{B} 2$ order transformation in $\mathrm{Fe}_{3} \mathrm{Al}$ alloys with dilute ternary substitutions for $\mathrm{Fe}$ [30]. We made measurements on alloys of $\mathrm{Fe}_{3-\mathrm{X}} \mathrm{AlX}_{\mathrm{X}}$, where the ternary solutes were $\mathrm{X}=$ $\{\mathrm{Ti}, \mathrm{V}, \mathrm{Cr}, \mathrm{Zr}, \mathrm{Nb}, \mathrm{Mo}, \mathrm{Hf}, \mathrm{Ta}, \mathrm{W}\}$. The effects of the solutes on the critical temperatures were well-explained by an argument based on the differences in metallic radii of the $\mathrm{X}$ atom and the $\mathrm{Al}$ atom.

\section{Vibrational Entropy}

\section{A. Magnitude of Vibrational Entropy}

The free energy, $F$, of an alloy phase is:

$$
\mathrm{F}=\mathrm{E}-\mathrm{T}\left(\mathrm{S}_{\text {config }}+\mathrm{S}_{\text {vibr }}\right)
$$

The configurational entropy, $S_{\text {config, }}$ is well-known. Until now, however, the importance of the vibrational entropy contribution, $S_{\text {vibr }}$, has been essentially unknown or neglected improperly. Towards the end of this grant we made efforts to measure the size of the difference in $S_{\text {vibr }}$ between different alloy phases. This work used precision cryogenic calorimetry, and for a variety of alloys found values of $\Delta S_{\text {vibr }}$ in the range of $0.1-0.3$ $\mathrm{k}_{\mathrm{B}} /$ atom $[13,27,28,31,33,34]$.

We began a parallel effort to understand vibrational entropy by measuring differences in phonon densities of states in different alloy phases $[31,33,35]$. This work involved inelastic neutron scattering, and was performed at the High Flux Isotope Reactor at the Oak Ridge National Laboratory. Our Oak Ridge collaborators have been Drs. R. M. Nicklow, S. Spooner, and J. L. Robertson. The changes vibrational entropy predicted from the changes in the phonon DOS have generally been in good agreement with the measurements by calorimetry, and both methods have complemented each other nicely. It seems that determining changes in vibrational entropy by measuring inelastic neutron scattering will be a rich new direction for further work. 


\section{2 - June, 1995}

\section{Publications of Fultz acknowledging DoE BES support under grant}

DE-FG03-86ER45270

1. J. Okamoto, D. H. Pearson, C. C. Ahn, and B. Fultz, "EELS Analysis of the Electronic Structure and Microstructure of Metals", Chapter 8 in Transmission Electron Energy Loss Spectrometry in Materials Science, TMS EMPMD Monograph Series Vol. 2, M. Disko, C. C. Ahn, and B. Fultz, eds., (TMS, Warrendale, 1992) 183-216.

2. Brent Fultz, "Chemical Systematics of Iron-57 Hyperfine Magnetic Field Distributions in Iron Alloys", Chapter 1 in Mössbauer Spectroscopy Applied to Magnetism and Materials Science Vol. I, G. J. Long and Fernande Grandjean, eds., (Plenum Press, New York, 1993) 1-31.

3. B. Fultz, "Kinetics of short- and long-range B2 ordering in ternary alloys", J. Mater. Res. I (1992) 946-954.

4. G. Le Caër, P. Matteazzi, and B. Fultz, "A Microstructural Study of the Mechanical Alloying of Fe and Sn Powders", J. Mater. Res. Z(6) (1992) 1387-1395.

5. B. Fultz, "Kinetic States of Order in Highly Nonequilibrium Materials", in Ordering and Disordering in Alloys, A. R. Yavari, ed., (Elsevier, London, 1992) 31-42.

6. B. Fultz, "Pseudo-stable States", Philos. Mag. B 67 (1993) 253-262.

7. Z. Q. Gao and B. Fultz, "Transient B32-Like Order in Nonequilibrium FezAl" in Kinetics of Ordering Transformations in Metals, H. Chen and V. K. Vasudevan, eds. (TMS, Warrendale, 1992) 151-159.

8. T. A. Stephens, H. Kuwano, and B. Fultz, "Site Occupancies of Ternary Solutes in FeCo-X (X=Mo,W)", in Kinetics of Ordering Transformations in Metals, $H$. Chen and V. K. Vasudevan, eds. (TMS, Warrendale, 1992) 53-59.

9. B. Fultz, "Effects of Vacancy-Solute Interactions on the Kinetics of Ordering" in Kinetics of Ordering Transformations in Metals, H. Chen and V. K. Vasudevan, eds. (TMS, Warrendale, 1992) 121-130.

10. L. Anthony and B. Fultz, "Kinetics of $\mathrm{B} 2, \mathrm{D}_{3}$ and $\mathrm{B} 32$ ordering: Results from pair approximation calculations and Monte Carlo simulations", J. Mater. Res. 9 (1994) 348-356.

11. Z. Q. Gao and B. Fultz, "Transient B32-like order during the early stages of ordering in undercooled $\mathrm{Fe}_{3} \mathrm{Al}$ ”, Philos. Mag. B 67 (1993) 787-800.

12. D. H. Pearson, C. C. Ahn, and B. Fultz, "White lines and d-electron occupancies for the 3d and 4d transition metals", Phys. Rev. B 47 (1993) 8471-8478.

13. L. Anthony, J. K. Okamoto, and B. Fultz, "Vibrational Entropy of Ordered and Disordered Ni3Al, Phys. Rev. Lett. 70 (1993) 1128-1130. 
14. B. Fultz and Z.Q. Gao, "A Mössbauer spectrometry study of hyperfine magnetic fields and ordering in $\mathrm{Fe}_{3} \mathrm{Al}^{\prime}$, Nucl. Instr. and Methods in Phys. Res. B76 (1993) $115-120$.

15. T. F. Lindsey and B. Fultz, "Monte Carlo Simulations of Ordering Kinetics", in B. Fultz, R. W. Cahn, and D. Gupta, eds., Diffusion in Ordered Alloys, TMS EMPMD Monograph Series Vol. 3 (TMS, Warrendale, 1993) 91-106.

16. L. Anthony and B. Fultz, "CVM-Based Free Energy Estimates in Monte Carlo Simulations", in B. Fultz, R. W. Cahn, and D. Gupta, eds., Diffusion in Ordered Alloys, TMS EMPMD Monograph Series Vol. 3 (TMS, Warrendale, 1993) p. 107-114.

17. H. H. Hamdeh, S. A. Oliver, B. Fultz and Z. Q. Gao, "Structure and magnetic properties of sputtered thin films of Fe $0.79 \mathrm{Ge}_{0.21}$ ", J. Appl. Phys. 74 (1993) 5117-5123.

18. B. Fultz, "Kinetics of Disorder $\rightarrow$ Order Transformations: Thermodynamic Theory Versus Kinetic Rate Theory", in Statics and Dynamics of Alloy Phase Transformations, P. E. A. Turchi and A. Gonis, eds., (Plenum, New York, 1994) 669-672.

19. T. F. Lindsey and B. Fultz, "Microstructural dependence of vacancy diffusion in ordered alloys", J. Appl. Phys. 75 (1994) 1467-1472.

20. B. Fultz, Z-Q. Gao, H. H. Hamdeh, and S. A. Oliver, "Locál and nonlocal isomer shifts in bcc Fe-X Alloys (X=A1,Si,Ga,Ge)", Phys. Rev. B 49 (1994) 63126315 .

21. B. Fultz, "The Kinetic Stability of Alloys having Periodic Minimal Surface Microstructures", Philos. Mag. A 70 (1994) p. 607-619.

22. T. A. Stephens, W. Keune, and B. Fultz, "Mössbauer Effect Diffraction from Polycrystalline ${ }^{57} \mathrm{Fe}$ " Hyperfine Interactions, 92 (1994) pp. 1095-1100.

23. Z. Gao and B. Fultz, "Kinetics of Ordering in $\mathrm{Fe}_{3} \mathrm{Si}$ ", Hyperfine Interactions 94 (1994) p. 2361-2366.

24. C. Bansal, Z.Q. Gao, L. B. Hong, and B. Fultz, "Phases and phase stabilities of $\mathrm{Fe}_{3} \mathrm{X}$ alloys (X=Al, $\left.\mathrm{As}, \mathrm{Ge}, \mathrm{In}, \mathrm{Sb}, \mathrm{Si}, \mathrm{Sn}, \mathrm{Zn}\right)$ prepared by mechanical alloying", J. Appl. Phys.76 (1994) p. 5961-5966.

25. D. H. Pearson, C. C. Ahn, and B. Fultz, "Measurements of 3 d occupancy from Cu $\mathrm{L}_{2,3}$ electron energy loss spectra of rapidly quenched $\mathrm{CuZr}, \mathrm{CuTi}, \mathrm{CuPd}, \mathrm{CuPt}$, and CuAu", Phys. Rev. B 50 (1994) p. 12969-12972.

26. B. Fultz, L. Anthony, and Z.-Q. Gao, "Kinetics of Ordering in Alloys Far from Thermodynamic Equilibrium" in Solid-Solid Phase Transformations, W. C. Johnson, J. Howe, D. E. Laughlin, and W. A. Soffa, eds. (TMS, Warrendale, 1994) pp. $1007-1025$.

27. L. Anthony, L. J. Nagel, and B. Fultz, "Vibrational Entropy Differences in Intermetallic Compounds from Phonon Densities of States" in Solid-Solid Phase 
Transformations, W. C. Johnson, J. Howe, D. E. Laughlin, and W. A. Soffa, eds. (TMS, Warrendale, 1994) pp. 467-472.

28. L. Anthony, L. J. Nagel, J. K. Okamoto, and B. Fultz "The magnitude and origin of the difference in vibrational entropy between ordered and disordered $\mathrm{Fe}_{3} \mathrm{Al}^{\prime \prime}$, Phys. Rev. Lett. 73 (1994) 3034.

29. J. K. Okamoto, C. C. Ahn, and B. Fultz, "Short-range ordering in fcc Ni3 $\mathrm{Al}^{\text {", J. }}$ Appl. Phys. 77 (1995) p. 4380-4383.

30. L. Anthony and B. Fultz, "Effects of early transition metal solutes on the $\mathrm{DO}_{3}-\mathrm{B} 2$ critical temperature in $\mathrm{Fe}_{3} \mathrm{Al}^{\prime \prime}$, Acta Metall. Mater. 43 (1995) 3885-3891.

31. B. Fultz, L. Anthony, J. L. Roberston, R. M. Nicklow, S. Spooner, and M. Mostoller, "Phonon Modes and Vibrational Entropy of Mixing in Fe-Cr", Phys. Rev. B 52 (1995) 3280-3285.

33. B. Fultz, L. Anthony, L. J. Nagel, R. M. Nicklow and S. Spooner, "Phonon densities of states and vibrational entropies of ordered and disordered $\mathrm{Ni}_{3} \mathrm{Al}^{\prime}$, Phys. Rev. B $\underline{52}$ (1995) 3315-3321.

34. L. J. Nagel, L. Anthony, J. K. Okamoto, and B. Fultz, "An experimental study of the difference in vibrational entropy between ordered and disordered $\mathrm{Fe}_{3} \mathrm{Al}^{\text {", }}$ submitted to the Proceedings of the Hume-Rothery Symposium in Honor of David Pettifor, G. M. Stocks and P. E. A. Turchi, eds., TMS Annual Meeting, 1995, submitted.

35. B. Fultz, J. L. Robertson, T. A. Stephens, L. J. Nagel and S. Spooner, "Phonon density of states of nanocrystalline Fe prepared by high energy ball milling", J. Appl. Phys. 79 (1996) p. 8318-8322.

36. L.Q. Chen, B. Fultz, J. W. Cahn, J. R.Manning, J. E. Morral and J. Simmons, eds., Mathematics of Microstructure Evolution, joint publication of (TMS, Warrendale, PA) TMS ISBN No. 0-87339-351-1 and (SIAM, Philidelphia, PA) SIAM ISBN No. 0-89871-386-2.

37. B. Fultz and L. Anthony, "The Thermal Stability of Alloys having Periodic Minimal Surface Microstructures", in Mathematics of Microstructure Evolution, L.Q. Chen, B. Fultz, J. W. Cahn, J. R.Manning, J. E. Morral and J. Simmons, eds., joint publication of (TMS, Warrendale, PA, 1996) TMS ISBN No. 087339-351-1 and (SIAM, Philidelphia, PA, 1996) SIAM ISBN No. 0-89871386-2. pp. 39-48.

\section{2 - 1996 Ph.D. theses supervised with at least partial support from DoE BES}

Hao Ouyang, "Grain Boundaries of Nanophase Materials", Ph.D. in Materials Science, California Institute of Technology, October 12, 1992.

Presently: Assistant Professor of Materials Science, National Chung Hsing University, Taiwan 
James Okamoto, "Temperature-Dependent Extended Electron Energy Loss Fine Structure Measurements from K, $\mathrm{L}_{23}$, and $\mathrm{M}_{45}$ Edges in Metals, Intermetallic Alloys, and Nanocrystalline Materials", Ph.D. in Applied Physics, California Institute of Technology, May 6, 1993.

Presently: Law student, Stanford University

Lawrence Anthony, "Kinetics of Disorder $\rightarrow$ Order Transformations in Highly Nonequilibrium Materials", Ph.D. in Materials Science, California Institute of Technology, May 24, 1993.

Presently: Assistant Professor of Physics, University of Toledo. Toledo, Ohio

Zheng-Qiang Gao, "The Kinetics of Ordering, Grain Growth, and Chemical Segregation in Nonequilibrium $\mathrm{Fe}_{3} \mathrm{X}$ Alloys $(\mathrm{X}=\mathrm{Al}$, Si, and $\mathrm{Ge})$ ", $\mathrm{Ph} . \mathrm{D}$. in Materials Science, California Institute of Technology, May 18, 1994.

Presently: Assistant to President on Engineering, Intex Corp., Long Beach, CA

Part of Prof. Nagel's support was derived from this grant, and part from the follow-on support from DoE:

Laura Jeanne Nagel, "Vibrational Entropy Differences in Materials", Ph.D. in Materials Science, California Institute of Technology, June 18, 1996.

presently: Assistant Professor of Engineering Technology, West Texas A\&M Univ., Amarillo, TX 